\title{
Advanced PAP Therapies and Non-invasive Ventilation
}

Editors

LEE K. BROWN

SHAHROKH JAVAHERI

\section{SLEEP MEDICINE CLINICS}

www.sleep.theclinics.com

Consulting Editor

TEOFILO LEE-CHIONG Jr

December 2017 • Volume 12 • Number 4 